\title{
Antiarrhythmic Effect of Acupuncture Pretreatment in Rats Subjected to Simulative Global Ischemia and Reperfusion - Involvement of Adenylate Cyclase, Protein Kinase A, and L-Type $\mathrm{Ca}^{2+}$ Channel
}

\author{
Junhong GAO${ }^{1}$, Ling ZHANG ${ }^{2}$, Yumin WANG ${ }^{2}$, Bo LU ${ }^{3}$, Haifeng $\mathrm{CUI}^{3}$, Weixing $\mathrm{FU}^{1}$, \\ Hongxin $\mathrm{WANG}^{2}$, Youhua $\mathrm{YU}^{3}$, and Xiaochun $\mathrm{YU}^{3}$ \\ 1Department of Physiology, Institute of Acupuncture, China Academy of Chinese Medical Sciences; \\ 2Department of Pharmacology, Liaoning Medical College; and ${ }^{3}$ Department of Physiology, Experimental Research Center, \\ China Academy of Chinese Medical Sciences
}

\begin{abstract}
Our previous study showed that electro-acupuncture (EA) pretreatment protects the heart from injury of ischemia. The present study explored further whether adenylate cyclase $(\mathrm{AC})$, protein kinase $\mathrm{A}(\mathrm{PKA})$, and L-type $\mathrm{Ca}^{2+}$ channel, the $\beta_{1}$-AR signaling components modulating intracellular $\mathrm{Ca}^{2+}$ $\left(\left[\mathrm{Ca}^{2+}\right]\right)$, are involved in the mediation of the antiarrhythmic effect of EA pretreatment in the rats from which the hearts were subsequently isolated and subjected to simulative global ischemia and reperfusion (SGIR). SGIR was performed by perfusing the isolated heart at a low flow followed by normal perfusion. Adult rats were randomized into four groups, namely, normal control (NC), SGIR, EA, and NC plus EA (NCEA) groups. The rats in the EA and NCEA groups were given EA pretreatment at bilateral Neiguan points (PC6) for 30 min once a day in 3 consecutive days before the hearts were isolated
\end{abstract}

and perfused. The arrhythmia score and the response of $\left[\mathrm{Ca}^{2+}\right]$ to the activators of $\mathrm{AC}, \mathrm{PKA}$, and $\mathrm{L}$-type $\mathrm{Ca}^{2+}$ channel in single ventricular myocyte isolated from the hearts subjected to SGIR were compared among the groups. The results showed that the arrhythmia score was significantly higher in the SGIR group as compared with the NC and NCEA groups. The SGIR-enhanced arrhythmia score was significantly attenuated in the EA group. More interesting, EA pretreatment also attenuated the SGIRenhanced response of $\left[\mathrm{Ca}^{2+}\right]_{i}$ to the activators of AC, PKA, and the L-type $\mathrm{Ca}^{2+}$ channel in the myocytes isolated from the hearts subjected to SGIR. In conclusion, EA pretreatment can produce an antiarrhythmic effect in the rat of SGIR. AC, PKA and the L-type $\mathrm{Ca}^{2+}$ channel are involved in the mediation of the antiarrhythmic effect of EA pretreatment.

Key words: electro-acupuncture pretreatment, arrhythmia, adenylate cyclase, protein kinase A, L-type $\mathrm{Ca}^{2+}$ channel.

\begin{abstract}
A rrhythmia is one of the most typical clinical manifestations in patients with cardiac ischemia and reperfusion. It is well documented that overactivation of the sympathetic nervous system is an important factor in the genesis of ventricular arrhythmias in patients with impaired ventricular function [1]. It is well known that $\beta_{1^{-}}$ adrenoceptor $\left(\beta_{1}-\mathrm{AR}\right)$, which acts as the most powerful cardiac receptor, is stimulated by the sympathetic neurotransmitters. The activation of cardiac $\beta$-adrenoceptors ( $\beta$-ARs) by the agonists of $\beta$-ARs, including isoproterenol and norepinephrine, causes the arrhythmias [2,3]. The wide use of $\beta_{1}$-AR blockers in the treatment of arrhythmias [4] further confirms the involvement of $\beta_{1}$-AR in the genesis of cardiac arrhythmias.

Similar to the cardioprotection produced by ischemic preconditioning, repetitive stimulation to either $\beta_{1}$-AR
\end{abstract}

or the components of its signaling pathway before myocardial ischemia and reperfusion (MIR) could attenuate the myocardial injury induced by the following prolonged ischemia and reperfusion [5-7]. Thus repetitive pretreatment with electro-acupuncture (EA), which was shown to excite the sympathetic nervous system, may also produce the cardioprotective effect via influencing $\beta_{1}$-AR and/or its signaling pathway. The results of our previous study showed that pretreatment with EA at bilateral Neiguan acupoints protects the heart from the injuries of ischemia and reperfusion via the inhibition of cardiac $\beta_{1}-$ AR and Gs-protein [8]. Since arrhythmias are the major manifestation of cardiac injury induced by ischemia and reperfusion, EA pretreatment may also ameliorate MIR-induced arrhythmias by blunting the $\beta_{1}$-AR signaling. The previous study showed that the

Received on May 7, 2008; accepted on Sep 14, 2008; released online on Oct 10, 2008; doi:10.2170/physiolsci.RP007108

Correspondence should be addressed to: Xiaochun Yu, Department of Physiology, Experimental Research Center, China Academy of Chinese Medical Sciences, No. 16 Nanxiaojie, Dongzhimennei, Dongcheng District, Beijing 100700, P.R. China.

Tel: +86-10-64014411 (Ext. 2775), Fax: +86-10-64013968, E-mail: yuxc@mail.cintcm.ac.cn 
intracellular calcium is related to the arrhythmogenesis [9]. During the MIR, the increase in intracellular $\mathrm{Ca}^{2+}$ $\left(\left[\mathrm{Ca}^{2+}\right]_{\mathrm{i}}\right)$ is associated with early afterdepolarization and consequently results in cardiac arrhythmias [10]. The factors affecting cytosolic $\mathrm{Ca}^{2+}$ are documented to be involved in the cause of arrhythmias [11, 12]. The purpose of the present study was to determine whether adenylate cyclase (AC), protein kinase A (PKA), as well as L-type $\mathrm{Ca}^{2+}$ channel, the $\beta_{1}$-AR signaling components modulating $\left[\mathrm{Ca}^{2+}\right]_{\text {i }}$, are involved in the mediation of the antiarrhythmic effect of EA pretreatment at bilateral Neiguan (PC6) acupoints by measuring the response of $\left[\mathrm{Ca}^{2+}\right]_{i}$ to forskolin, an activator of $\mathrm{AC}$, to 8-Br-cAMP, an activator of PKA, and to Bay K-8644, an opener of the L-type $\mathrm{Ca}^{2+}$ channel in the single ventricular myocyte isolated from the rats subjected to the simulative global ischemiareperfusion (SGIR). It was shown that pretreatment with EA can attenuate the increased responsiveness of $\left[\mathrm{Ca}^{2+}\right]_{\mathrm{i}}$ in SGIR-subjected cardiac myocytes to the activators of $\mathrm{AC}, \mathrm{PKA}$, and L-type $\mathrm{Ca}^{2+}$ channel. The results indicated that the components of the $\beta_{1}$-AR signaling pathway, including $\mathrm{AC}$ and PKA, as well as L-type $\mathrm{Ca}^{2+}$ channel, are involved in the mediation of the antiarrhythmic effect of EA pretreatment in the rats subjected to SGIR.

\section{METHODS}

Electro-acupuncture pretreatment. The present study was approved by the Committee on the Use of Live Animals in Research of the China Academy of Chinese Medical Sciences. Male Sprague-Dawley rats weighing 266-320 g were randomly divided into four groups, namely, normal control (NC), simulative global ischemiareperfusion (SGIR), electro-acupuncture (EA), and NC plus EA (NCEA). Before the experiments, the animals in the EA and NCEA groups were pretreated with EA applied at bilateral Neiguan acupoints (PC6, according to the textbook of experimental acupuncture, Neiguan acupoint is located on the forelimbs) for 30 min once a day for three consecutive days. For the acupuncture manipulation, two needles, 2-3 mm apart, were inserted through the skin to a depth of about $2 \mathrm{~mm}$ at each Neiguan acupoint. These two needles were connected to positive and negative poles of an acupuncture apparatus. The stimulatory intensity and frequency of EA were $5 \mathrm{~mA}$ and 20 $\mathrm{Hz}$, respectively.

Langendorff perfused isolated rat heart preparation. The Langendorff perfused isolated rat hearts were prepared for the study of arrhythmias as described previously [13]. In brief, male Sprague-Dawley rats weighing 190 to $210 \mathrm{~g}$ were sacrificed by decapitation with a guillotine. The hearts were removed immediately and perfused retrogradely with a Krebs-Ringer solution containing (in mM) $115 \mathrm{NaCl}, 5 \mathrm{KCl}, 1.2 \mathrm{MgSO}_{4}, 1.2 \mathrm{KH}_{2} \mathrm{PO}_{4}, 1.25$ $\mathrm{CaCl}_{2}, 25 \mathrm{NaHCO}_{3}$, and 11 glucose with $1 \%$ dialyzed bo- vine serum albumin. The solution was aerated with $95 \%$ $\mathrm{O}_{2}$ and $5 \% \mathrm{CO}_{2}, \mathrm{pH} 7.4$, under a pressure of $55-70 \mathrm{mmHg}$ and a constant flow rate of $13 \mathrm{ml} / \mathrm{min}$. The temperature of the hearts was maintained at $36^{\circ} \mathrm{C}$. The first $10 \mathrm{~min}$ of perfusion allowed them to stabilize, and any heart exhibiting arrhythmia during this period was discarded. The hearts in the SGIR group or the EA group were initially perfused at a rate of $13 \mathrm{ml} / \mathrm{min}$ for $10 \mathrm{~min}$, which was followed by a reduced-flow perfusion at a rate of $0.5 \mathrm{ml} / \mathrm{min}$ for $40 \mathrm{~min}$. After reduced-flow perfusion, the perfusing flow was restored to the control level for $10 \mathrm{~min}$. The hearts were perfused at a constant flow rate of $13 \mathrm{ml} / \mathrm{min}$ without reduced-flow perfusion for $60 \mathrm{~min}$ in the $\mathrm{NC}$ and NCEA groups. Although there were occasional arrhythmias during the low-flow period, arrhythmias were much more frequent when the flow was restored, as observed in previous studies [14] and in our preliminary study. In the present study we determined the arrhythmias in the 10 min period after the flow had been restored, namely, the reperfusion.

Measurement of ECG and the arrhythmia scoring system. ECG was continuously monitored with standard lead II throughout the experiment with a positive electrode hooked to the apex of the heart and a negative electrode at the aorta. A typical ECG trace consists of a P-wave and a QRS complex, which occurs at regular intervals. Both atrial arrhythmias, including premature atrial contraction (PAC), and ventricular arrhythmias, including premature ventricular contraction (PVC), ventricular tachycardia (VT), and ventricular fibrillation (VF), were observed within 10 min after restoration of normal perfusion in the present study. VT and VF were defined as a successive run of at least 6 PVCs of uniform and irregular QRS complex, respectively. Three or more PVCs occurring within 1 min were considered frequent. The occurrence of fewer than 3 was considered occasional.

To enable quantitative comparison, a scoring system modified from that in previous studies $[15,16]$ was adopted. The principles it employed were (1) ventricular arrhythmias being more severe than atrial arrhythmias; (2) the severity of ventricular arrhythmias being VF, VT, frequent PVC, and occasional PVC in descending order; (3) the longer the duration of arrhythmias or the more frequent their incidence, the greater their severity. In the present study, the score of a heart was that of the most severe type of arrhythmia the heart exhibited. The details of the scoring system are shown in Table 1.

Isolated ventricular myocytes. Ventricular myocytes of male adult Sprague-Dawley rats were isolated using a collagenase perfusion method, as described previously [17]. Immediately after a 60 min perfusion (60 min normal perfusion in the NC and NCEA groups and $10 \mathrm{~min}$ normal perfusion +40 min low flow perfusion $+10 \mathrm{~min}$ normal reperfusion in the SGIR and EA groups), the heart was then continuously perfused at a constant flow of 10 
Table 1. An arrhythmia scoring system.

\begin{tabular}{cl}
\hline Arrhythmia score & Type of arrhythmia \\
\hline 0 & No arrhythmia \\
1 & Atrial arrhythmias or occasional PVC \\
2 & Frequent PVC \\
3 & VT (1-2 episodes) \\
4 & VT (>3 episodes) or VF (1-2 episodes)
\end{tabular}

$\mathrm{ml} / \mathrm{min}$ with oxygenated Joklik-modified Eagle medium supplemented with $1.25 \mathrm{mM} \mathrm{CaCl}_{2}$ and $10 \mathrm{mM}$ HEPES, $\mathrm{pH} 7.4$, at $37^{\circ} \mathrm{C}$ for $5 \mathrm{~min}$, followed by another $5 \mathrm{~min}$ with the same solution without $\mathrm{Ca}^{2+}$. Type I collagenase was added to the medium to a concentration of $125 \mathrm{U} / \mathrm{ml}$ with $0.1 \%$ bovine serum albumin. After $35-45$ min of perfusion with the collagenase-containing medium, both atria were discarded. The ventricular tissues from the heart subjected to both normal perfusion and SGIR were cut into small pieces by a pair of scissors and stirred by a glass rod in the same oxygenated collagenase solution for $5 \mathrm{~min}$ at $37^{\circ} \mathrm{C}$. The residue was filtered through a $250 \mu \mathrm{m}$ mesh screen with $2 \%$ bovine serum albumin. More than $70 \%$ of the cells were rod shaped and not trypan blue permeable. The $\mathrm{Ca}^{2+}$ concentration of the Joklik solution was increased gradually to $1.25 \mathrm{mM}$ in $30 \mathrm{~min}$.

Loading of cells with fura-2/AM. For measurement of the electrically induced $\left[\mathrm{Ca}^{2+}\right]_{\mathrm{i}}$ transient, the cells were first loaded with fura-2/AM as a $\mathrm{Ca}^{2+}$ indicator, and $\left[\mathrm{Ca}^{2+}\right]_{\mathrm{i}}$ transient was determined by a spectrofluorometric method described previously $[18,19]$. Isolated ventricular myocytes were incubated with fura-2/AM at a concentration of $4 \mu \mathrm{M}$ in a Joklik solution supplemented with 1.25 $\mathrm{mM} \mathrm{CaCl}_{2}$ for $25 \mathrm{~min}$. To remove the unincorporated dye, the cells were washed with fresh incubation solution and twice centrifuged $1 \mathrm{~min}$ at $80-100 \mathrm{~g}$. The loaded cells were resuspended in Krebs-Henseleit buffer and maintained at room temperature $\left(24^{\circ}-26^{\circ} \mathrm{C}\right)$ for $60 \mathrm{~min}$ before measurement of $\left[\mathrm{Ca}^{2+}\right]_{\mathrm{i}}$ in order to allow the fura-2/AM in the cytosol to de-esterify.

Measurement of cytosolic free $\left[\mathrm{Ca}^{2+}\right]_{i}$. The apparatus and fura-2 fluorescent technique have been described previously [20]. The ventricular myocytes loaded with fura-2/AM were transferred to the stage of an inverted microscope (Nikon Corp.) in a superfusion chamber at room temperature. The inverted microscope was coupled with a dual excitation spectrofluorometer (Intracellular Imaging, Inc.). The ventricular myocytes were superfused with a Krebs-Ringer solution as subscribed above with $1 \%$ dialyzed bovine serum albumin and gassed with $95 \% \mathrm{O}_{2}-5 \% \mathrm{CO}_{2}$. The electrical field stimulation with 15 ms duration at $0.2 \mathrm{~Hz}$ produced by a stimulator was added to the myocytes. Fluorescence excitation was provided from a mercury lamp, and wavelengths were selected by computer-controlled movement of two interference filters
(340 and $380 \mathrm{~nm}$ ) into the light path of the microscope. A wheel-installed two excitation filters rotated at a rate of $60 \mathrm{~Hz}$. A dichroic mirror was used to separate the excitation and emission components in the filter container. Emission $(510 \mathrm{~nm})$ was collected by a photomultiplier tube (PMT). The signal from the PMT was processed by a computer and displayed digitally on the computer screen. The fluorescence ratio of $340 \mathrm{~nm}$ (F340) over $380 \mathrm{~nm}$ (F380) was used as an index of $\left[\mathrm{Ca}^{2+}\right]_{i}$ because changes in the fluorescence ratio were considered to accurately reflect the fluctuations in the cytosolic $\mathrm{Ca}^{2+}$ of the contraction-relaxation cycle.

Drugs and chemicals. Type I collagenase, fura-2/AM, forskolin, 8-Br-cAMP, and Bay K-8644 were purchased from Sigma-Aldrich Co. All chemicals were dissolved in distilled water except fura-2/AM, Bay K-8644, and forskolin, which were dissolved in diethyl sulphoxide (DMSO). The final concentration of DMSO was less than $0.1 \%$, which itself has no effect on $\left[\mathrm{Ca}^{2+}\right]_{\mathrm{i}}$.

Statistical analysis. All data in the present study were presented as mean $\pm \mathrm{SE}$. A one-way ANOVA and $t$-test were used to analyze the data in different groups. A $P$ value of less than 0.05 was considered as statistical significance.

\section{RESULTS}

\section{The effects of pretreatment with EA on cardiac arrhythmias in rats subject to SGIR}

Figure 1 shows the changes in arrhythmic scores evaluated by the aforementioned scoring system in different groups. Figure 1A shows the representative tracings of ECG recorded in NC, SGIR, EA, and NCEA groups, and Fig. $1 \mathrm{~B}$ is the statistical graphics among the groups. The arrhythmic score was zero in the NC and NCEA groups, suggesting that there was no arrhythmia. In the SGIR group there were different arrhythmias induced by myocardial ischemia and reperfusion, including atrial and ventricular arrhythmias. The arrhythmic score was 3.21 \pm 0.73 in this group. With the pretreatment of EA before SGIR, the arrhythmias produced by ischemia and reperfusion were significantly blunted in the EA group, exhibiting a lower arrhythmic score of $1.24 \pm 0.67$.

\section{Effect of EA pretreatment on the forskolin- induced increase in $\left[\mathrm{Ca}^{2+}\right]_{i}$ transient in single cardiac myocyte isolated from the rat hearts subjected to SGIR}

Figure $2 \mathrm{~A}$ shows the representative tracings of $\left[\mathrm{Ca}^{2+}\right]_{\mathrm{i}}$ transient in the single ventricular myocyte in response to forskolin stimulation in NC, SGIR, EA, and NCEA groups; Fig. 2B is the statistical graphics among the groups. The amplitude of electrically induced $\left[\mathrm{Ca}^{2+}\right]_{\mathrm{i}}$ transient in the single cardiac myocyte was enhanced by $77.07 \pm 3.95 \%$ by forskolin, an activator of $\mathrm{AC}$, at a con- 
A $\mathrm{NC}$

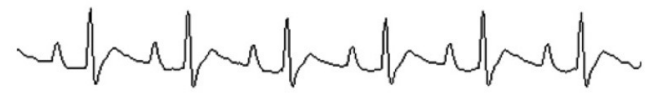

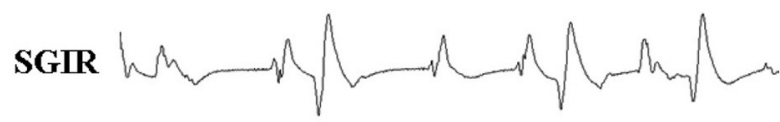

EA

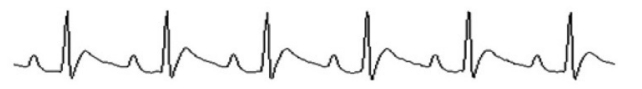

NCEA

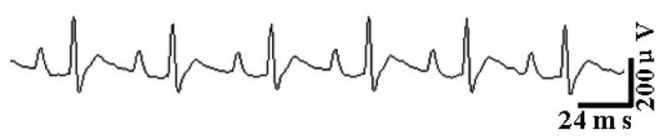

$\mathbf{B}$

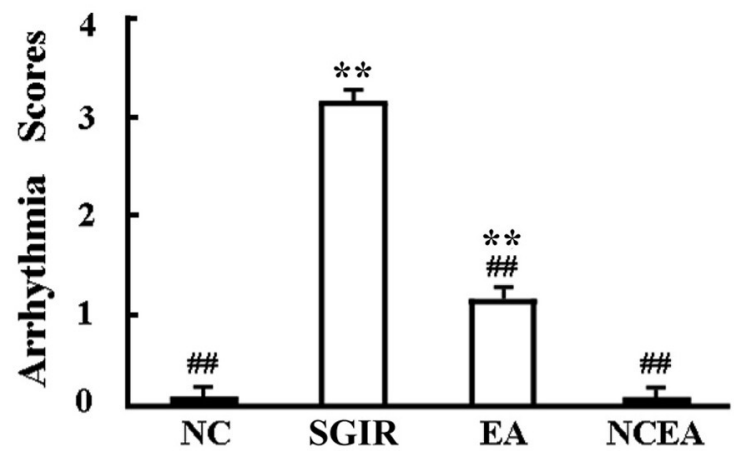

A
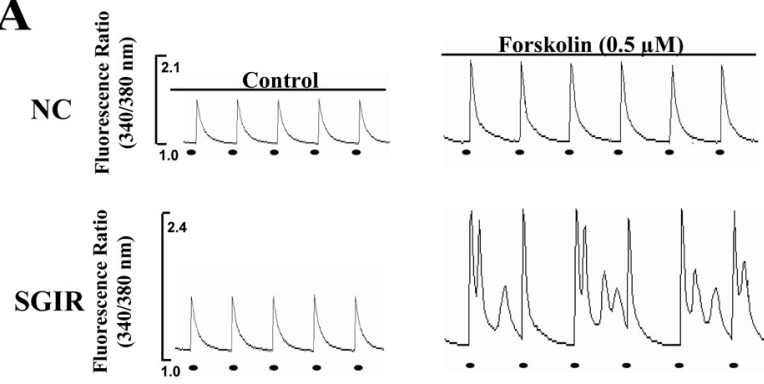

EA

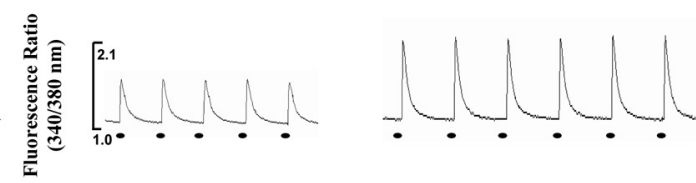

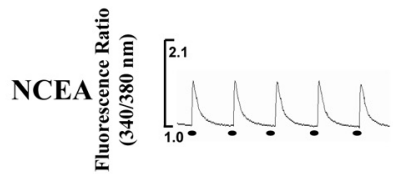

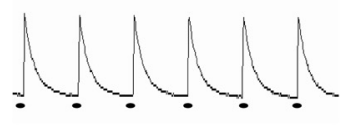

B

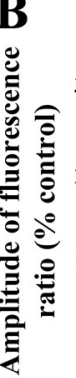

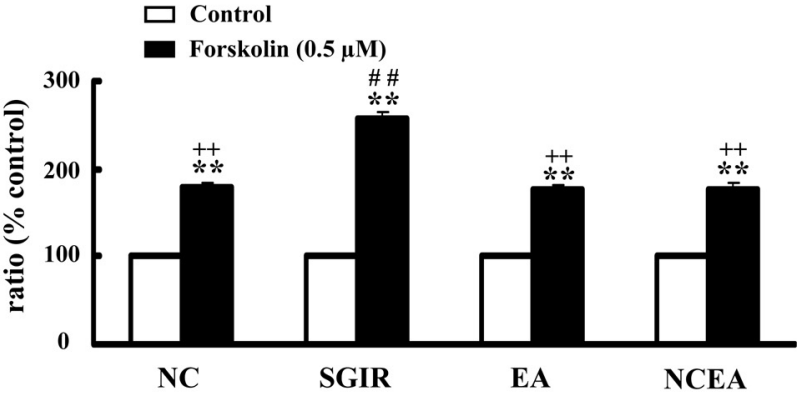

Fig. 1. Effect of EA pretreatment on cardiac arrhythmias in the isolated heart subjected to simulative global ischemia and reperfusion. Panel A: Representative traces of ECG showing the cardiac arrhythmias in the rats of different groups. Panel B: Statistical results of arrhythmic scores evaluating the cardiac arrhythmias recorded 10 min after reperfusion in the different groups. NC, normal control group; SGIR, simulative global ischemia and reperfusion group; EA, electro-acupuncture group; NCEA, normal control plus electro-acupuncture group. ${ }^{* *} P<$ 0.01 as compared with NC group; ${ }^{\#} P<0.05$ in comparison with SGIR group ( $n=10$ in each group above).
Fig 2. Effect of EA pretreatment on the response of $\left[\mathrm{Ca}^{2+}\right]_{i}$ to forskolin in single ventricular myocyte isolated from perfused heart subjected to simulative global ischemia and reperfusion. Panel A: Representative traces of $\mathrm{Ca}^{2+}$ transient in single ventricular myocyte of different groups. Panel B: Statistical results of amplitude of an electrically induced $\left[\mathrm{Ca}^{2+}\right]_{i}$ transient in a single ventricular myocyte of different groups. ${ }^{* *} P<0.01$ vs. corresponding control; ${ }^{\#} P<0.01$ as compared with the corresponding NC group; ${ }^{++} P<0.01$ in comparison with the corresponding SGIR group. All the myocytes were stimulated by an electrical field with a duration of $15 \mathrm{~ms}$ and a frequency of 0.2 Hz. - Electrical stimulation ( $n=12$ in each group). 
A
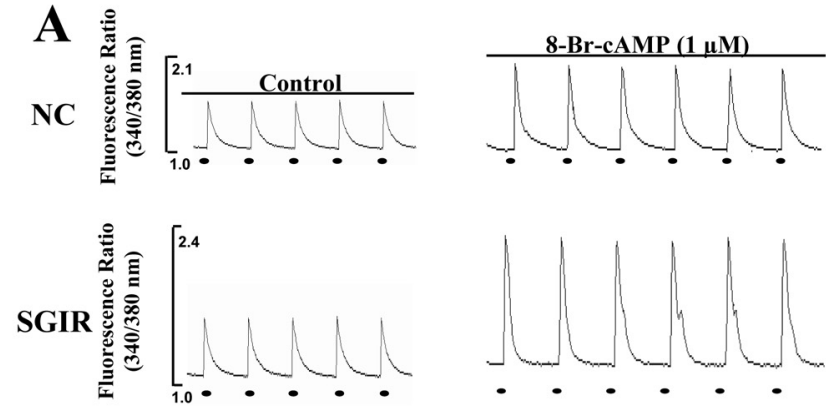

EA
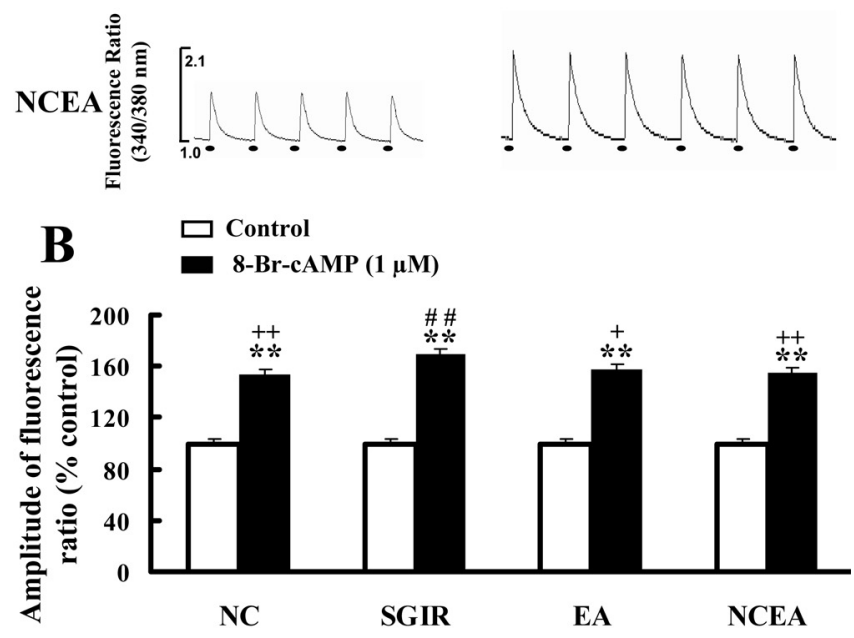

centration of $0.5 \mu \mathrm{M}$ in the $\mathrm{NC}$ group; The augmentation in the amplitude of $\left[\mathrm{Ca}^{2+}\right]_{\mathrm{i}}$ transient caused by forskolin in the NCEA group was $77.67 \pm 4.07 \%$, almost the same as that in the NC group. In the SGIR group, the isolated hearts were subjected to simulative global ischemia followed by reperfusion. The amplitude of $\left[\mathrm{Ca}^{2+}\right]_{\mathrm{i}}$ transient was elevated by $157.87 \pm 7.89 \%$ by the same concentration of forskolin in the SGIR group, which is significantly higher than that in the NC group $(P<0.01)$. As mentioned above, in the EA group the rats were pretreated with EA three times in three consecutive days before the hearts were isolated and subjected to the SGIR. It is interesting that the augmentation in the amplitude of $\left[\mathrm{Ca}^{2+}\right]_{\mathrm{i}}$ transient caused by forskolin is $78.41 \pm 4.92 \%$ in the EA group, which was much lower than that in the SGIR group $(P<$ 0.01 ) and almost the same as that in the NC group.

\section{Effect of EA pretreatment on the 8-Br-cAMP- induced increase in $\left[\mathrm{Ca}^{2+}\right]_{i}$ transient in single cardiac myocyte isolated from the rat hearts subjected to SGIR}

Figure 3A shows the representative tracings of intracellular $\mathrm{Ca}^{2+}$ transient in the single ventricular myocyte
Fig. 3. Effect of EA pretreatment on the response of $\left[\mathrm{Ca}^{2+}\right]_{\mathrm{i}}$ to 8-Br-cAMP in single ventricular myocyte isolated from a perfused heart that was subjected to simulative global ischemia and reperfusion. Panel A: Representative traces of $\mathrm{Ca}^{2+}$ transient in single ventricular myocyte of different groups. Panel B: Statistical results of amplitude of an electrically induced $\left[\mathrm{Ca}^{2+}\right]_{2}$ transient in a single ventricular myocyte of different groups. ${ }^{* *} P$ $<0.01$ vs. corresponding control; $\# P<0.01$ as compared with the corresponding NC group; ${ }^{+} P<0.05,{ }^{++} P<0.01$ in comparison with the corresponding SGIR group. All the myocytes were stimulated by an electrical field with a duration of $15 \mathrm{~ms}$ and a frequency of $0.2 \mathrm{~Hz}$. Electrical stimulation ( $n=12$ in each group).

in response to 8-Br-cAMP stimulation in the NC, SGIR, EA, and NCEA groups; Fig. 3B shows the statistical graphics among the groups; 8-Br-cAMP, an activator of PKA, caused different augmentations in the amplitude of electrically induced $\left[\mathrm{Ca}^{2+}\right]_{\mathrm{i}}$ transient in the single cardiac myocyte. The percentage of the augmentation was 68.92 $\pm 3.65 \%$ in the SGIR group, which is significantly higher than $54.15 \pm 2.70 \%$ in the NC group $(P<0.01)$. In the EA group, the augmentation in the amplitude of $\left[\mathrm{Ca}^{2+}\right]_{\mathrm{i}}$ transient caused by 8 -Br-cAMP was $57.36 \pm 3.44 \%$, which is much lower than that in the SGIR group $(P<0.05)$. The amplitude of $\left[\mathrm{Ca}^{2+}\right]_{i}$ transient was elevated by $54.83 \pm$ $2.89 \%$ by the same concentration of 8 -Br-cAMP in the NCEA group.

\section{Effect of EA pretreatment on the Bay K-8644- induced increase in $\left[\mathrm{Ca}^{2+}\right]_{\mathrm{i}}$ transient in single cardiac myocyte isolated from the rat hearts subjected to SGIR}

Figure 4A shows the representative tracings of intracellular $\mathrm{Ca}^{2+}$ transient in the single ventricular myocyte in response to Bay K-8644 stimulation in the NC, SGIR, EA, and NCEA groups; Fig. 4B is the statistical graph- 


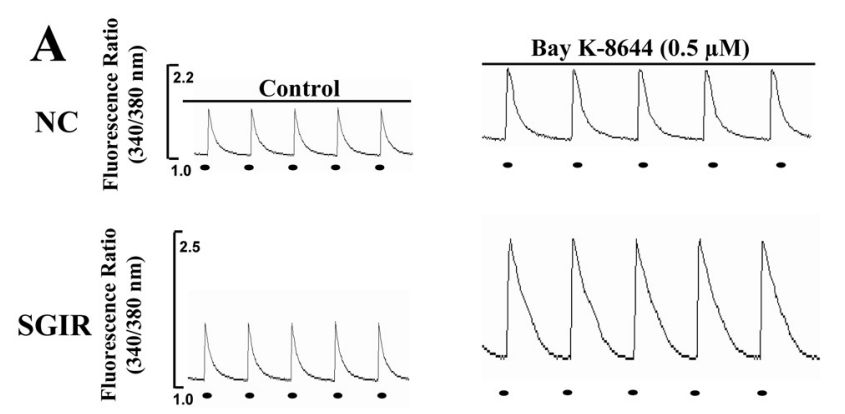

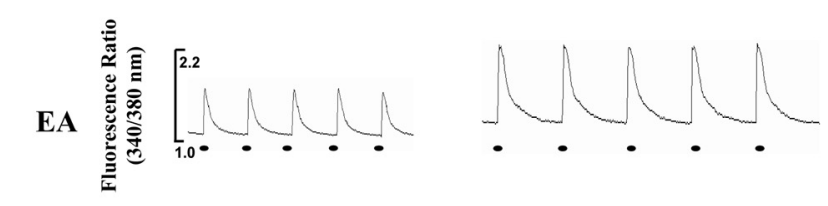
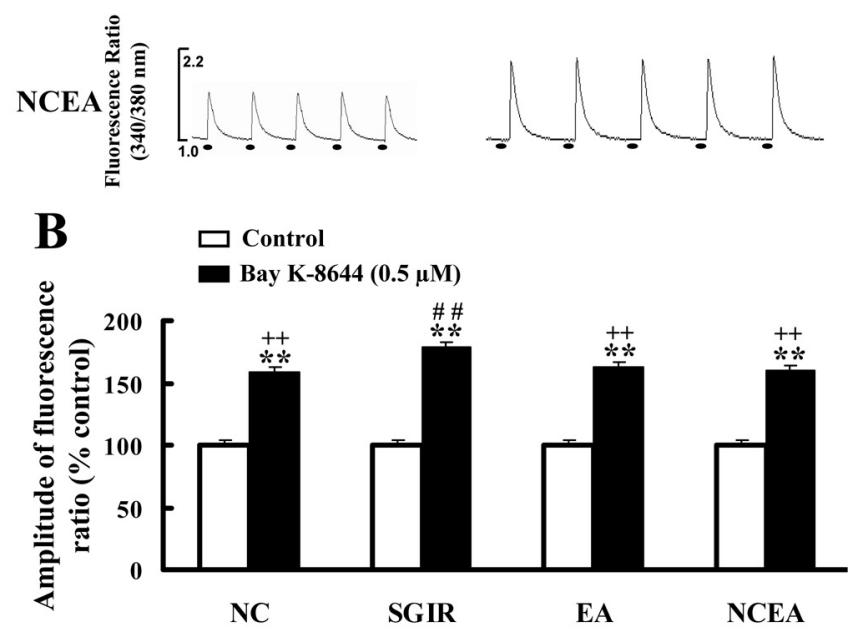

ics among the groups. As shown in Fig. 4, Bay K-8644, a specific opener of L-type $\mathrm{Ca}^{2+}$ channel, caused different augmentations in the amplitude of electrically induced $\left[\mathrm{Ca}^{2+}\right]_{\mathrm{i}}$ transient in the above different groups. The percentage of the augmentation was $78.02 \pm 4.90 \%$ in the SGIR group, which is significantly higher than $59.06 \pm$ $2.95 \%$ in the NC group $(P<0.01)$. In the EA group, the augmentation in the amplitude of $\left[\mathrm{Ca}^{2+}\right]_{\mathrm{i}}$ transient caused by Bay K-8644 is $62.17 \pm 5.11 \%$, much lower than that in the SGIR group $(P<0.01)$; and the amplitude of $\left[\mathrm{Ca}^{2+}\right]_{\mathrm{i}}$ transient was elevated $60.11 \pm 3.07 \%$ by the same concentration of Bay K-8644 in the NCEA group.

\section{DISCUSSION}

During MIR, both the sympathetic activity to the heart [21-23] and the cardiac responsiveness to the sympathetic influence [23] are increased. This consequently increases $\left[\mathrm{Ca}^{2+}\right]_{\text {i }}$, which has been shown to contribute to arrhythmias $[24,25]$. It is well established that $\beta_{1}$-AR stimulation causes the increase in $\left[\mathrm{Ca}^{2+}\right]_{i}$, even $\left[\mathrm{Ca}^{2+}\right]_{\mathrm{i}}$ overload [26, 27], which may induce arrhythmias [24], via increases in cAMP production [28] and influx of $\mathrm{Ca}^{2+}$
Fig. 4. Effect of $E A$ pretreatment on the response of $\left[\mathrm{Ca}^{2+}\right]_{i}$ to Bay K-8644 in single ventricular myocyte isolated from perfused heart subjected to simulative global ischemia and reperfusion. Panel A: Representative traces of $\mathrm{Ca}^{2+}$ transient in a single ventricular myocyte of different groups. Panel B: Statistical results of amplitude of an electrically induced $\left[\mathrm{Ca}^{2+}\right]_{i}$ transient in a single ventricular myocyte of different groups. ${ }^{* *} P$ $<0.01$ vs. corresponding control; ${ }^{\# \#} P<0.01$ as compared with the corresponding NC group; ${ }^{++} P<0.01$ in comparison with the corresponding SGIR group. All the myocytes were stimulated by an electrical field with a duration of $15 \mathrm{~ms}$ and a frequency of $0.2 \mathrm{~Hz}$. Electrical stimulation ( $n=12$ in each group).

across the L-type $\mathrm{Ca}^{2+}$ channel $[26,29]$. Further studies showed that most components of the signaling pathway of $\beta_{1}$-AR were involved in the occurrence of cardiac arrhythmias. Activation of adenylate cyclase by forskolin led to arrhythmia-related cytosolic $\mathrm{Ca}^{2+}$ oscillation [30] and an enhancement of cytosolic cAMP production [31]. An activator of protein kinase A, 8-Br-cAMP, which phosphorylates the $\mathrm{Ca}^{2+}$ cycling proteins, can also cause atrial and ventricular arrhythmias [32]. Furthermore, the various cardiac arrhythmias were reported to be induced by Bay K-8644, a specific L-type $\mathrm{Ca}^{2+}$ channel opener [33]. It was observed in our previous study that the contents of $\beta_{1}-A R, G_{s \alpha}$ protein, and cAMP were increased in the cardiac myocytes subjected to ischemia and reperfusion [8], and EA pretreatment could prevent the myocardium from the injury induced by ischemia and reperfusion by inhibiting the increased contents of $\beta_{1}-A R, G_{s \alpha}$ protein, and cytosolic cAMP, the components of $\beta_{1}$-AR signaling pathway. However, it is still not known whether the signaling components other than $\beta_{1}-A R, G_{s \alpha}$ protein, and cytosolic cAMP in $\beta_{1}$-AR signal transduction pathway are involved in the mediation of the antiarrhythmic effect of EA pretreatment. The aim of the present study 
is to further explore the undiscovered mechanisms. The present results showed that severe arrhythmia was produced by SGIR, and the response of $\left[\mathrm{Ca}^{2+}\right]_{i}$ to the activators of AC, PKA, and L-type $\mathrm{Ca}^{2+}$ channel in the myocytes subjected to SGIR were also enhanced, suggesting that these components of the $\beta_{1}$-AR signaling pathway were involved in the mediation of myocardial injury and arrhythmias induced by myocardial ischemia and reperfusion.

It was found previously that cyclic brief ischemic preconditioning can protect the heart from injury induced by subsequent longer ischemia. Stimulating $\beta_{1}$-AR with norepinephrine prior to ischemia can also mimic ischemic preconditioning to attenuate the ischemic myocardial injury $[6,7]$. AC, PKA, and L-type $\mathrm{Ca}^{2+}$ channel are the important components of the $\beta_{1}$-AR signaling pathway, and all of them were reported to contribute to the cardioprotection of ischemic preconditioning [34-36]. Based on these findings, we hypothesized the involvement of either AC, PKA, or L-type $\mathrm{Ca}^{2+}$ channel, the $\beta_{1}$-AR signaling components other than $\beta_{1}$-AR itself, Gs protein, and cAMP in the mediation of the antiarrhythmic effect produced by EA pretreatment. Furthermore, the intracellular calcium is well-known to be strongly modulated by $\beta_{1}$-AR stimulation, and the increase or overload of intracellular calcium is associated with the arrhythmogenesis [37]. For example, the arrhythmia-related delayed afterdepolarizations can be produced by catecholaminergic stimulation, known to stimulate mainly the beta-adrenergic receptors, by increasing the intracellular calcium [38], and similarly, early afterdepolarizations can also be induced by an LCC opener such as Bay K-8644 [39]. It was also demonstrated that acupuncture at the acupoints of Stomach Meridian of Foot-Yangming enhanced significantly the intracellular calcium in gastric smooth muscle cells. All the findings above suggest that acupuncture may produce the antiarrhythmic effect via influencing the arrhythmogenic $\left[\mathrm{Ca}^{2+}\right]_{i}$ or its modulators, including $\beta_{1}$-AR signaling components. Thus we determined the response of $\left[\mathrm{Ca}^{2+}\right]_{\mathrm{i}}$ in cardiac myocytes subjected to SGIR to the activators of $\mathrm{AC}$ and PKA and the opener of L-type $\mathrm{Ca}^{2+}$ channel, the important components of the $\beta_{1}$-AR signaling pathway. As we supposed, EA pretreatment can produce antiarrhythmic effect in the rat of SGIR, which was supported by the data showing that the SGIR-induced augment of arrhythmia score was significantly attenuated after repetitive EA pretreatment. Of greater interest, the further experiments showed that pretreatment with EA also attenuated the SGIR-increased response of $\left[\mathrm{Ca}^{2+}\right]_{i}$ to the activators of $\mathrm{AC}, \mathrm{PKA}$, and the L-type $\mathrm{Ca}^{2+}$ channel in single cardiomyocytes, suggesting that $\mathrm{AC}$, PKA, and L-type $\mathrm{Ca}^{2+}$ channel are involved in the mediation of the antiarrhythmic effect of the acupuncture pretreatment. Moreover, EA stimulation was shown to significantly enhance the sympathetic activity [40]. Theoretically, the augmented sympathetic activity can consequently increase the release of catecholamine that stimulates cardiac $\beta_{1}$-AR and finally enhances the $\left[\mathrm{Ca}^{2+}\right]_{\mathrm{i}}$. As mentioned above, there was a study showing that acupuncture at the acupoints of Stomach Meridian of Foot Yangming enhanced the resting $\left[\mathrm{Ca}^{2+}\right]_{\mathrm{i}}$ in the smooth muscle cells isolated from stomachs of the normal rabbits. Strangely, our present data showed that EA pretreatment did not significantly influence the $\left[\mathrm{Ca}^{2+}\right]_{\mathrm{i}}$ transient in the single cardiomyocyte isolated from the normal rats in the NCEA group. A reasonable explanation for the unchanged $\left[\mathrm{Ca}^{2+}\right]_{\mathrm{i}}$ following the EA pretreatment in the normal rats is that although EA can enhance the $\left[\mathrm{Ca}^{2+}\right]_{\mathrm{i}}$ momentarily during the stimulation by exciting the sympathetic activity to stimulate the cardiac $\beta_{1}-\mathrm{AR}$, the enhanced $\left[\mathrm{Ca}^{2+}\right]_{\mathrm{i}}$ may restore to the normal level after the procedures of cell isolation from heart and fura-2/AM loading to the cells. However, in the present study the enhancement of $\left[\mathrm{Ca}^{2+}\right]_{i}$ induced by ischemia and reperfusion was not restored to the normal level even after the same procedures of cell isolation and fura-2 loading in the SGIR group, which is in agreement with the recent study on the role played by $\left[\mathrm{Ca}^{2+}\right]_{\mathrm{i}}$ in the MIR. The results suggest that the impairment of the mechanisms of handling $\left[\mathrm{Ca}^{2+}\right]_{\mathrm{i}}$ may be too severe to be recovered in the period. As described in Methods of the present study, the rats were pretreated with EA three times in three consecutive days before the cardiomyocytes were isolated from the perfused heart subjected to SGIR. The EA pretreatment-induced repetitive enhancement-restoration cycles of $\left[\mathrm{Ca}^{2+}\right]_{\mathrm{i}}$ via stimulating cardiac $\beta_{1}$-AR may mimic the repetitive ischemic preconditioning to produce the cardioprotective effect in the rats subjected to SGIR. The underlying mechanisms for the cardioprotection produced by EA pretreatment may be to induce the possible adaptation (or desensitization) of the cardiomyocytes isolated from the heart with SGIR to the stimulation of $\beta_{1}$-AR and its signaling components, which are overactivated during ischemia and reperfusion.

\section{CONCLUSION}

The results indicate that the repetitive EA pretreatment can produce antiarrhythmic effect by inhibiting the function of $\mathrm{AC}, \mathrm{PKA}$, and the L-type $\mathrm{Ca}^{2+}$ channel.

The present study was supported by National Natural Science Foundation of China (NSFC) Grant 30572417 and National Basic Research Program (also called 973 Program) of China Grant 2006CB504506, as well as Beijing Natural Science Foundation Grant 7072053.

\section{REFERENCES}

1. Podrid PJ, Fuchs T, Candinas R. Role of the sympathetic nervous system in the genesis of ventricular arrhythmia. Circulation. 1990;82(Suppl I):I103-13.

2. Martins JB. Sympathetic influences in myocardial ischemia: possible mechanisms of arrhythmogenesis. Cardiol Clin. 1983;1:51-61. 
3. Schömig A, Richardt G, Kurz T. Sympatho-adrenergic activation of the ischemic myocardium and its arrhythmogenic impact. Herz. 1995;20:169-86.

4. Mallet RT, Ryou MG, Williams AG Jr, Howard L, Downey HF. Beta1Adrenergic receptor antagonism abrogates cardioprotective effects of intermittent hypoxia. Basic Res Cardiol. 2006;101:436-46.

5. Cain BS, Meldrum DR, Meng X, Shames BD, Banerjee A, Harken AH. Calcium preconditioning in human myocardium. Ann Thorac Surg. 1998:65:1065-70.

6. Frances C, Nazeyrollas P, Prevost A, Moreau F, Pisani J, Davani S, Kantelip JP, Millart H. Role of beta 1- and beta 2-adrenoceptor subtypes in preconditioning against myocardial dysfunction after ischemia and reperfusion. J Cardiovasc Pharmacol. 2003:41:396-405.

7. Nasa Y, Yabe K, Takeo S. Beta-adrenoceptor stimulation-mediated preconditioning-like cardioprotection in perfused rat hearts. J Cardiovasc Pharmacol. 1997;29:436-43.

8. Gao J, Fu W, Jin Z, Yu X. Acupuncture pretreatment protects heart from injury in rats with myocardial ischemia and reperfusion via inhibition of the $\beta 1$ adrenoceptor signaling pathway. Life Sci. 2007;80:1484-9.

9. Venetucci LA, Trafford AW, O'Neill SC, Eisner DA. The sarcoplasmic reticulum and arrhythmogenic calcium release. Cardiovasc Res. 2008;77:285-92.

10. Burashnikov A, Antzelevitch C. Reinduction of atrial fibrillation immediately after termination of the arrhythmia is mediated by late phase 3 early afterdepolarization-induced triggered activity. Circulation. 2003;107:2355-60.

11. Minamisawa S, Sato Y, Cho MC. Calcium cycling proteins in heart failure, cardiomyopathy and arrhythmias. Exp Mol Med. 2004;36:193-203.

12. Lehnart SE, Wehrens XH, Laitinen PJ, Reiken SR, Deng SX, Cheng Z, Landry DW, Kontula K, Swan H, Marks AR. Sudden death in familial polymorphic ventricular tachycardia associated with calcium release channel (ryanodine receptor) leak. Circulation. 2004;109:3208-14.

13. Xia Q, Sheng JZ, Tai KK, Wong TM. Effects of chronic U50,488H treatment on binding and mechanical responses of the rat hearts. J Pharmacol Exp Ther. 1994;268:930-4.

14. Fenton RA, Galeckas KJ, Dobson JG Jr. Endogenous adenosine reduces depression of cardiac function induced by beta-adrenergic stimulation during low flow perfusion. J Mol Cell Cardiol. 1995;27:2373-83

15. Curtis MJ, Walker MJ. Quantification of arrhythmias using scoring systems: an examination of seven scores in an in vivo model of regional myocardial ischaemia. Cardiovasc Res. 1988:22:656-65.

16. Wong TM, Lee AY, Tai KK. Effects of drugs interacting with opioid receptors during normal perfusion or ischemia and reperfusion in the isolated rat heart - an attempt to identify cardiac opioid receptor subtype(s) involved in arrhythmogenesis. J Mol Cell Cardiol. 1990;22:1167-75.

17. Dong H, Sheng JZ, Lee CM, Wong TM. Calcium antagonistic and antiarrhythmic actions of CPU-23, a substituted tetrahydroisoquinoline. Br J Pharmacol. 1993;109:113-9.

18. Yu XC, Li HY, Wang HX, Wong TM. U50,488H inhibits effects of norepinephrine in rat cardiomyocytes: cross-talk between $\kappa$-opioid and $\beta$-adrenergic receptors. J Mol Cell Cardiol. 1998;30:405-13.

19. Zhang WM, Wang HX, Xia Q, Wong TM. Inhibition of [3H]-U69593 binding and the cardiac effects of $\mathrm{U} 50,488 \mathrm{H}$ by calcium channel blockers in the rat heart. Br J Pharmacol. 1997;120:827-32.

20. Hohl CM, Li QA. Compartmentation of CAMP in adult canine ventricular myocytes. Relation to single-cell free $\mathrm{Ca}^{2+}$ transients. Circ Res. 1991;69:1369-79.

21. Bernauer $W$. Effect of exogenous adenosine deaminase on arrhythmias and the release of adenine nucleotide catabolites in isolated rat hearts with coronary occlusion and reperfusion. Naunyn Schmiedebergs Arch Pharmacol. 1991;344:544-50.
22. Boachie-Ansah G, Kane KA, Parratt JR. Is adenosine an endogenous myocardial protective (antiarrhythmic) substance under conditions of ischaemia? Cardiovasc Res. 1993;27:77-83.

23. Schömig A, Richardt G. Cardiac sympathetic activity in myocardial ischemia: release and effects of noradrenaline. Basic Res Cardiol. 1990;85 Suppl 1:9-30

24. Lakatta EG, Guarnieri T. Spontaneous myocardial calcium oscillations: are they linked to ventricular fibrillation? J Cardiovasc Electrophysiol. 1993:4:473-89

25. Thandroyen FT, Morris AC, Hagler HK, Ziman B, Pai L, Willerson JT, Buja LM. Intracellular calcium transients and arrhythmia in isolated heart cells. Circ Res. 1991;69:810-9.

26. Hussain M, Orchard $\mathrm{CH}$. Sarcoplasmic reticulum $\mathrm{Ca}^{2+}$ content, L-type $\mathrm{Ca}^{2+}$ current and the $\mathrm{Ca}^{2+}$ transient in rat myocytes during beta-adrenergic stimulation. J Physiol. 1997;505:385-402.

27. Wang X, Wang J, Takeda S, Elimban V, Dhalla NS. Alterations of cardiac beta-adrenoceptor mechanisms due to calcium depletion and repletion. Mol Cell Biochem. 2002;232:63-73.

28. Podzuweit T, Els DJ, McCarthy J. Cyclic AMP mediated arrhythmias induced in the ischaemic pig heart. Basic Res Cardiol. 1981;76:443-8.

29. Tsien RW, Bean BP, Hess P, Lansman JB, Nilius B, Nowycky MC. Mechanisms of calcium channel modulation by beta-adrenergic agents and dihydropyridine calcium agonists. J Mol Cell Cardiol. 1986;18:691-710.

30. Eschenhagen T, Mende U, Diederich M, Hertle B, Memmesheimer C Pohl A, Schmitz W, Scholz H, Steinfath M, Böhm M, Michel MC, Brodde OE, Raap A. Chronic treatment with carbachol sensitizes the myocardium to cAMP-induced arrhythmia. Circulation. 1996;93:763-71.

31. Yajima H, Komatsu M, Schermerhorn T, Aizawa T, Kaneko T, Nagai M, Sharp GW, Hashizume K. cAMP enhances insulin secretion by an action on the ATP-sensitive $\mathrm{K}^{+}$channel-independent pathway of glucose signaling in rat pancreatic islets. Diabetes. 1999;48:1006-12.

32. Podzuweit T. Catecholamine-cyclic-AMP-Ca+-induced ventricular tachycardia in the intact pig heart. Basic Res Cardiol. 1980;75:772-9.

33. Yu XC, Wang HX, Pei JM, Wong TM. Anti-arrhythmic effect of kappa-opioid receptor stimulation in the perfused rat heart: involvement of a CAMP. dependent pathway. J Mol Cell Cardiol. 1999;31:1809-19.

34. Lochner A, Genade S, Tromp E, Podzuweit T, Moolman JA. Ischemic preconditioning and the beta-adrenergic signal transduction pathway. Circulation. 1999;100:958-66.

35. Tabrizchi R, Triggle CR. Comparison between the vasoactive actions of endothelin and arginine vasopressin in pithed rats after pretreatment with BAY K 8644, nifedipine or pertussis toxin. J Pharmacol Exp Ther. 1990;253:272-6.

36. Tong H, Bernstein D, Murphy E, Steenbergen C. The role of beta-adrenergic receptor signaling in cardioprotection. FASEB J. 2005;19:983-5.

37. Ter Keurs HE, Boyden PA. Calcium and arrhythmogenesis. Physiol Rev. 2007:87:457-506

38. Tweedie D, Harding SE, MacLeod KT. Sarcoplasmic reticulum Ca content, sarcolemmal $\mathrm{Ca}$ influx and the genesis of arrhythmias in isolated guinea-pig cardiomyocytes. J Mol Cell Cardiol. 2000;32:261-72.

39. Volders PG, Vos MA, Szabo B, Sipido KR, de Groot SH, Gorgels AP, Wellens HJ, Lazzara R. Progress in the understanding of cardiac early afterdepolarizations and torsades de pointes: time to revise current concepts. Cadiovasc Res. 2000;46:376-92.

40. Lin TB, Fu TC, Chen CF, Lin YJ, Chien CT. Low and high frequency electroacupuncture at Hoku elicits a distinct mechanism to activate sympathetic nervous system in anesthetized rats. Neurosci Lett. 1998:247:155-8. 